\title{
Análise comparativa entre a coloração do azul de toluidina e a imunoexpressão da ciclina D1 em leucoplasias da mucosa bucal com diferentes graus de atipia
}

\author{
Comparative analysis between the coloring of toluidine blue and the immuno- \\ expression of cyclin D1 in leucoplakias of the bucal mucosa with different degrees of \\ atipia
}

Lorena Ferraz Santos Silva ${ }^{1}$, Luciana Maria Pedreira Ramalho ${ }^{2 *}$

${ }^{1}$ Mestranda em Processos Interativos dos Órgãos e Sistemas. Instituto de Ciências da Saúde. Universidade Federal da Bahia - UFBA; ${ }^{2}$ Doutora em Estomatologia Clínica. Pontifícia Universidade Católica do Rio Grande do Sul.

\begin{abstract}
Resumo
O câncer de boca ocupa uma posição de destaque em relação ao número total de casos registrados no Brasil. A displasia epitelial (DE) oral é um achado histopatológico associado a um risco aumentado de transformação maligna do epitélio oral. A falha nos mecanismos de sinalização celular, no controle do ciclo celular ou nos mecanismos para reparar danos celulares pode favorecer a processos que culminam com a progressão para o câncer. Objetivo: avaliar comparativamente a resposta clínica da marcação do azul de toluidina (AT) e a imunoexpressão da proteína ciclina D1, uma proteína nuclear de grande importância como regulador da transição da fase G1 para fase S do ciclo celular, em leucoplasias oral (LO). Metodologia: avaliamos 12 pacientes que apresentavam, na cavidade bucal, lesões com diagnóstico clínico de LO. O estudo se desenvolveu em duas etapas: clínica e laboratorial. Foi feita marcação com AT e avaliação Imuno-histoquímica, respectivamente. Após análise quantitativa das lâminas, os dados obtidos foram analisados pelo programa BIOESTAT 2.0, por meio dos testes de Spearman e pelo teste de correlações múltiplas de Pearson. Resultados: não foi observada relação entre a marcação clínica do AT, o grau de displasia da lesão e a imunoexpressão da Ciclina D1 em LO. Conclusão: $82 \%$ das lesões apresentaram DE em graus variados, confirmando a necessidade de se realizar o diagnóstico histopatológico das LO e o acompanhamento clínico posterior dos pacientes.
\end{abstract}

Palavras-chave: Leucoplasia. Ciclina D1. Carcinoma espinocelular.

\begin{abstract}
Mouth cancer occupies a prominent position in relation to the total number of cases registered in Brazil. Oral epithelial dysplasia (ED) is a histopathological finding associated with an increased risk of malignant transformation of oral epithelium. The failure in the mechanisms of cell signaling, cell cycle control mechanisms or to repair cell damage can favor processes that culminate with the progression to cancer. Objective: evaluate comparatively the clinical response of the toluidine blue marking (TB) and immuno-expression of cyclin $D 1$ protein, a nuclear protein of great importance as a factor regulating the transition from G1 phase to $S$ phase of the cell cycle, in oral leukoplakia (OL). Methodology: we evaluated 12 patients who presented lesions in the oral cavity with clinical diagnosis of OL. The study was developed in two stages: Clinical and Laboratorial. Marking was made with TB and immunohistochemical evaluation, respectively. After quantitative analysis of blades, the data obtained were analyzed by BIOESTAT program 2.0 through Spearman tests and by Pearson multiple correlation test. Results: no relation was observed between clinical marking of TB, the degree of dysplasia of the lesion and the immuno-expression of Cyclin D1 in OL. Conclusion: $82 \%$ of the lesions presented DE in varying degrees, confirming the need to perform histopathological diagnosis of the $O L$ and the subsequent clinical monitoring of the patients.
\end{abstract}

Keywords: Leukoplakia. Cyclin D1. Spinocell Carcinoma.

\section{INTRODUÇÃO}

O câncer de boca ocupa uma posição de destaque em relação ao número total de casos registrados no Brasil. Essa lesão, na grande maioria dos casos, é representada pelo carcinoma espinocelular (CEC) o qual se origina da camada escamosa do epitélio da mucosa bucal e corresponde a cerca de 90 a $95 \%$ dos tumores malignos nessa localização anatômica ${ }^{1}$. Mesmo com o avanço da

Correspondente/Corresponding: * Luciana Maria Pedreira Ramalho - End: Avenida Araújo Pinho, 62 Canela CEP:40110-150 - E-mail: lucianaramalho@uol.com.br - Tel:(71) 99904-3168 tecnologia em saúde, o diagnóstico do câncer de boca ainda ocorre nos estágios mais avançados da doença. Em razão disso, a sobrevida dos pacientes é drasticamente reduzida, e muitos casos deixam de ser identificados nos momentos em que seria possível interceptar a progressão da carcinogênese, ou possibilitar o tratamento do câncer nos seus momentos iniciais, aumentando a sobrevida livre de doença dos pacientes, com impacto na morbimortalidade pela adoção de terapêutica menos mutiladora.

$\mathrm{Na}$ mucosa oral, o conceito de processo de duas etapas no desenvolvimento do câncer está bem estabelecido, com a possibilidade de estabelecimento inicial de 
uma lesão com potencial de malignização posterior ${ }^{2}$. A displasia epitelial oral (DEO) é um achado histopatológico associado a um risco aumentado de transformação maligna do epitélio oral $\left.\right|^{3,4}$. A Organização Mundial da Saúde (OMS) descreve a displasia como um epitélio alterado, que mostra várias alterações celulares e estruturais na superfície da camada epitelial, como resultado de alterações genéticas acumuladas 5 . Estima-se que a DEO afeta $0,25 \%$ a $0,5 \%$ das populações ${ }^{4}$. Clinicamente, pode se apresentar como uma lesão branca, vermelha ou mista, categorizada em distúrbios orais potencialmente malignos (DOPM), que precedem o câncer oral em até $70 \%$ dos casos ${ }^{6}$.

O câncer oral tem a sexta maior taxa de mortalidade entre todos os outros cânceres ${ }^{7}$, e o carcinoma de células escamosas oral (CCEO) é o subtipo histológico mais comum $^{7,8}$. Lesões potencialmente malignas (LPMs) na cavidade bucal é um fator de risco para o desenvolvimento do CCEO. O exame histopatológico deve ser administrado para detectar displasia epitelial oral (DEO) como um indicador para transformação e progressão maligna ${ }^{9}$. No entanto, a progressão para o fenótipo maligno não é observada na maioria das $\mathrm{LPMs}^{10}$.

A falha nos mecanismos de sinalização celular, no controle do ciclo celular ou nos mecanismos para reparar danos celulares pode favorecer processos que, após várias etapas, culminam com a progressão para o câncer ${ }^{11}$. É importante compreender os mecanismos e os controles do ciclo celular no câncer oral humano não só para a compreensão biológica da doença, mas também com fins de diagnóstico precoce e terapêutica ${ }^{12}$.

No ciclo celular, as ciclinas mitóticas e as ciclinas da fase $\mathrm{G} 1$ desempenham papel importante em cada etapa do ciclo. As primeiras são essenciais para o controle do ciclo celular na transição G2/M (mitose), enquanto as ciclinas $\mathrm{G1}$ são essenciais para o controle do ciclo celular na transição $\mathrm{G} 1 / \mathrm{S}^{13}$. A ciclina $\mathrm{D}$ possui três isoformas, $\mathrm{D} 1$, D2 e D3, e está envolvida na regulação da progressão do ciclo celular na transição de fase G1 / S e parece responder a estímulos de crescimento externo e não a controles internos do ciclo celular ${ }^{14}$.

A ciclina D1 é a melhor ciclina do tipo D descrita e frequentemente associada ao controle do ciclo celular e da oncogênese. A ciclina D1 está localizada no cromossomo $11 q 13$, e níveis elevados induzem a apoptose ${ }^{13}$. Entretanto, a ciclina D1 é um oncogene importante, pois sua superexpressão leva ao encurtamento da fase G1 e à menor dependência de mitógenos exógenos, resultando em proliferação celular anormal que, por sua vez, pode favorecer a ocorrência de lesões genéticas adicionais ${ }^{15}$. Alguns tumores epiteliais mostram a amplificação do gene da ciclina $\mathrm{D} 1^{16}$. Portanto, o excesso de ciclina D1 é o resultado do rearranjo genético ${ }^{17} \mathrm{e}$, consequentemente, a amplificação desse gene aparece frequentemente em tumores malignos ${ }^{18}$.

O tratamento usualmente recomendado para lesões leucoplásicas é cirúrgico, podendo, a depender da extensão da lesão e de suas características clínicas, requerer biópsia incisional. A modalidade de tratamento tradicional não elimina completamente o risco de transformação maligna, e, por isso, é importante o desenvolvimento de marcadores de prognósticos mais objetivos que identifiquem lesões de alto risco ${ }^{19}$. Nesse contexto, alguns métodos têm sido propostos com a finalidade de auxiliar na seleção do sítio de biópsia e na estimativa das características biológicas da lesão ${ }^{20}$, como a coloração pelo azul de toluidina (AT), um teste tecnicamente simples e de baixo custo.

A coloração pelo AT é a técnica de diagnóstico adjuvante mais utilizada para avaliar distúrbios da mucosa oral. Sua característica principal é que mancha seletivamente componentes ácidos do tecido. Esse teste é baseado no fato de que as células displásicas podem conter, quantitativamente, mais ácidos nucleicos, e um epitélio displásico também tem uma perda de coesão. Essas características facilitam a penetração, através do epitélio, e retenção do corante em células cancerígenas, que estão se replicando in vivo; já a mucosa normal não consegue reter o corante. O teste AT pode ser auxiliar no diagnóstico clínico, mas não substitui a análise histopatológica, que é o padrão ouro no diagnóstico de câncer oral21.

Dessa forma, para o estabelecimento do diagnóstico precoce do CEC, é de fundamental importância que os pacientes portadores das desordens potencialmente malignas sejam devidamente acompanhados, e que, tais lesões tenham seu comportamento biológico estabelecido, para a proposição de terapêutica mais individualizada. O presente trabalho objetiva avaliar comparativamente a resposta clínica da marcação do AT e a imunoexpressão da proteína ciclina D1, uma proteína nuclear de grande importância como regulador da transição da fase G1 para fase $\mathrm{S}$ do ciclo celular, em leucoplasias da mucosa bucal.

\section{METODOLOGIA}

\section{População e amostra}

No presente estudo, foram selecionados, no ambulatório de Estomatologia da Faculdade de Odontologia da Universidade Federal da Bahia, 12 pacientes que apresentavam, na cavidade bucal, lesões com diagnóstico clínico de leucoplasia, independentemente de sexo e raça dos pacientes, tamanho e localização das lesões nos sítios anatômicos intrabucais. Todos os pacientes incluídos na pesquisa assinaram o Termo de Consentimento Livre e Esclarecido.

O estudo se desenvolveu em duas etapas: clínica e laboratorial.

\section{Etapa clínica: coloração por azul de toluidina (1\%)}

Após se ter diagnosticado clinicamente a presença de leucoplasia na cavidade bucal dos pacientes (Figura 1), as lesões foram submetidas ao teste de coloração com azul de toluidina.

Técnica de coloração: (Baseada na técnica pro- 
posta NIEBEL, CHOMET) ${ }^{22}$ :

1. Aplicação do ácido acético a $1 \%$ sobre a lesão, com um cotonete, para remoção de material orgânico que possa existir em sua superfície.

2. Remoção o ácido acético com cotonete seco ou gaze.

3. Aplicação, com cotonete, do corante azul de toluidina a $1 \%$, sobre toda a superfície da lesão, sendo aguardado, no mínimo, 1 minuto para fixação do corante (Figura 2).

4. Nova aplicação do ácido acético a $1 \%$ para remoção do excesso de corante na superfície da lesão.

Os resultados obtidos com o azul de toluidina com relação à impregnação do corante foram descritos na ficha clínica do paciente e registrados da seguinte forma: como positiva (1) aquela em que a coloração foi evidente, independentemente de sua intensidade, e negativa (0) quando não foi observada coloração alguma.

A seleção do local de biópsia foi dependente do resultado da coloração. Nos casos de coloração homogênea negativa ou positiva em que foi possível, realizou-se biópsia excisional. Nos casos de marcação heterogênea, foram selecionadas duas áreas para se realizarem as biópsias incisionais nas áreas classificadas como positiva (1) e negativa (0).

Após a seleção, foram realizadas as biópsias, seguindo-se as regras de segurança e assepsia:

- Realização de antissepsia com clorexidina.

- Bloqueio nervoso terminal com anestésico local.

- Incisão da área previamente demarcada na lesão.

- Dissecção dos tecidos adjacentes.

- Remoção da peça cirúrgica.

- Sutura dos bordos e prescrição pós-operatória.

Os fragmentos removidos foram acondicionados em recipientes contendo solução de formol a $10 \%$, identificados como (1) positiva e ou (0) negativa.

\section{Etapa laboratorial}

Os espécimes com as peças foram encaminhados para o laboratório de Anatomia Patológica da Faculdade de Odontologia da Universidade Federal da Bahia, onde foram processados para técnica histológica de rotina e incluídos em parafina. Foram obtidos cortes de $5 \mu \mathrm{m}$ de espessura, os quais foram corados pela técnica da Hematoxilina e Eosina (H/E). Todas as seções histológicas foram examinadas pela microscopia de luz a fim de se verificar a presença ou não de displasia epitelial e, em caso afirmativo, seu grau de severidade.

As lâminas de cada caso foram submetidas a exame histológico para se analisar o grau de displasia das lesões, seguindo-se os parâmetros estabelecidos por Bánóczy e Csiba ${ }^{23}$. Observou-se, em cada seção, a presença ou não de estratificação epitelial irregular, hiperplasia da camada basal, processos reticulares em gota, perda de polaridade das células basais, aumento da razão núcleo e citoplasma, polimorfismo nuclear, aumento do tama- nho dos nucléolos, hipercromatismo nuclear, redução da aderência intercelular, mitoses suprabasais e disceratose - considerados parâmetros histológicos das displasias. Estabeleceram-se, posteriormente, os seguintes diagnósticos: ausência de displasia (quando menos de dois parâmetros estavam presentes), displasia leve (quando dois parâmetros estavam presentes), displasia moderada (quando de dois a quatro parâmetros estavam presentes) e displasia severa (quando cinco ou mais parâmetros estavam presentes). Após a avaliação da presença e do grau da displasia, foi realizada a coloração imuno-histoquímica com os anticorpos: anticorpo monoclonal NCL-CYCLIN D1-GM (NOVOCASTRA).

Nessa etapa, foram excluídos os cortes que se apresentavam inadequados para serem submetidos à marcação imuno-histoquímica.

\section{Marcação imuno-histoquímica}

\section{$\diamond$ Procedimentos iniciais}

Os cortes histológicos de $5 \mu \mathrm{m}$ de espessura foram posicionados em lâminas carregadas positivamente (Superfrost/plus microscope slides, Fisher Scientific) e processados pela técnica imuno-histoquímica da streptavidina-biotina (LSAB plus, peroxidase, Dako) (Figura 3). Todas as lâminas foram colocadas em estufa a 600C durante uma hora. Em seguida, procedeu-se à desparafinização por meio de três passagens por xilol, cinco minutos em cada etapa. Após o xilol, foram feitas três passagens de três minutos por álcool absoluto e uma passagem por água destilada.

\section{$\diamond$ Recuperação do antígeno}

Os procedimentos para a exposição dos sítios antigênicos nos cortes histológicos foram realizados em calor úmido, por 05 minutos, utilizando-se panela de pressão (PERFECT-Germany). As lâminas foram posicionadas em berços de plástico e imersas em $1000 \mathrm{ml}$ de tampão de Citrato 0,01M, ph-6,0. Em seguida, as lâminas permaneceram imersas na própria solução-tampão, em temperatura ambiente, durante 10 minutos, para que fossem resfriadas lentamente, e posteriormente submetidas à lavagem em água corrente.

\section{$\diamond \quad$ Bloqueio da peroxidase endógena}

O bloqueio da peroxidase endógena se deu com a imersão dos cortes histológicos por um período de 10 min, em uma solução com $190 \mathrm{ml}$ água destilada $10 \mathrm{ml}$ de H2O2 30\%. Após o bloqueio, as lâminas foram lavadas em água corrente e posicionadas em câmara úmida. Durante todas as etapas dos procedimentos imuno-histoquímicos, os cortes histológicos permaneceram úmidos.

\section{$\diamond$ Incubação dos anticorpos primários}

As lâminas foram lavadas com tampão TRIS-HCL para remoção do excesso de líquido. Em seguida, foram aplicadas alíquotas de $100 \mu \mathrm{l}$ dos anticorpos primários (anti-Ciclina D-1), diluídos em solução redutora de fundo 
(Antibody Diluent With Background Reducing Components, Dako). Para cada anticorpo primário avaliado, foram utilizados cortes para controle positivo e controle negativo. Como controle positivo das reações, foi utilizada tonsila. Como controle negativo, utilizaram-se os mesmos tecidos do controle positivo, porém com a substituição da alíquota do anticorpo primário por alíquota de tampão TRIS-HCL. Os controles positivos e negativos foram incubados juntamente com os grupos experimentais, durante um período de 40 minutos.

$\diamond$ Incubação do anticorpo secundário, do anticorpo terciário e do cromógeno

Após a lavagem com TRIS-HCL e remoção do excesso de líquido, o anticorpo secundário (100 $\mu \mathrm{l}$ por corte) foi incubado em todos os cortes durante 20 minutos. Em seguida, foi realizada outra lavagem com TRIS-HCL, para que o anticorpo terciário, (100 $\mu \mathrm{l}$ por corte) fosse aplicado e incubado por mais 10 minutos. Novamente foi feita a lavagem com TRIS-HCL, com intuito de se remover o excesso de líquido. Logo em seguida, incubou-se o cromógeno diaminobenzidina (DAB; DAKO) por 10 minutos (100 $\mu \mathrm{l}$ por corte). Para remover o DAB, as lâminas foram lavadas abundantemente em água corrente.

\section{$\diamond$ Contracoloração e montagem das lâminas}

Foi realizada com Hematoxilina de Harris, pelo tempo de 30 segundos. Em seguida, realizou-se lavagem em água corrente para a remoção do excesso do corante. Os cortes passaram por três sequências de três minutos, em álcool absoluto, e 3 sequências de xilol, também de três minutos cada uma. As lamínulas foram montadas em permount (FISHER Scientifics).

\section{Análise da marcação imuno-histoquímica}

Para a quantificação das marcações positivas de cada anticorpo, foi utilizado um microscópio óptico binocular (Zeiss-Standard 20) na objetiva de 40x. O referido microscópio estava acoplado a um sistema de câmera Samsung modelo SCC 131. As imagens foram obtidas pelo programa VIDEOCAP (Microsoft), licenciado para FOUFBA e analisadas pelo programa de computador IMAGELAB (Sistema de Processamento e Análise de Imagem - Softium Sistemas de Informática, São Paulo). Cada corte histológico foi analisado através da contagem de 1000 células epiteliais da esquerda para a direita da lâmina, de baixo para cima.

\section{Análise estatística}

Após a análise quantitativa das lâminas, os dados obtidos foram analisados pelo programa BIOESTAT 2.0 (SOCIEDADE CIVIL MAMIRAUÁ / MCT-CNPQ, Diretoria de Unidade de Pesquisa), através de testes estatísticos não paramétricos de Spearman e pelo teste de correlações múltiplas de Pearson, para níveis de significância de 5\%.
Figura 1- Demonstração da área de marcação positiva do AT (seta).

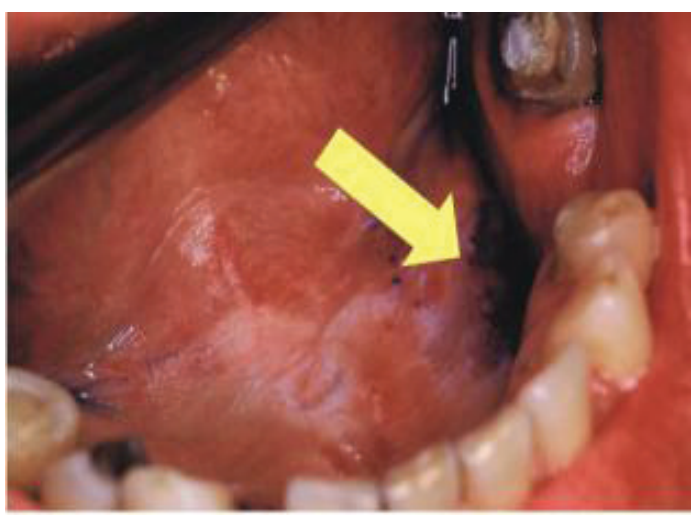

Fonte: Autoria própria

Figura 2 - Fotomicrografia do caso 02A. Observa-se a presença de células com hipercromatismo nuclear e estratificação epitelial irregular. (H/E, aumento aprox. 100x).

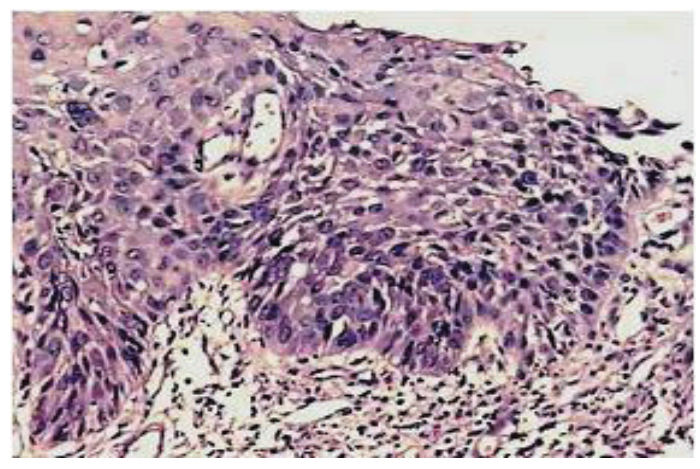

Fonte: Autoria própria

Figura 3 - Fotomicrografia do caso 05. Observa-se imunoexpressão nuclear difusa da Ciclina D1 (Streptavidina-biotina aumento aprox. 200x).

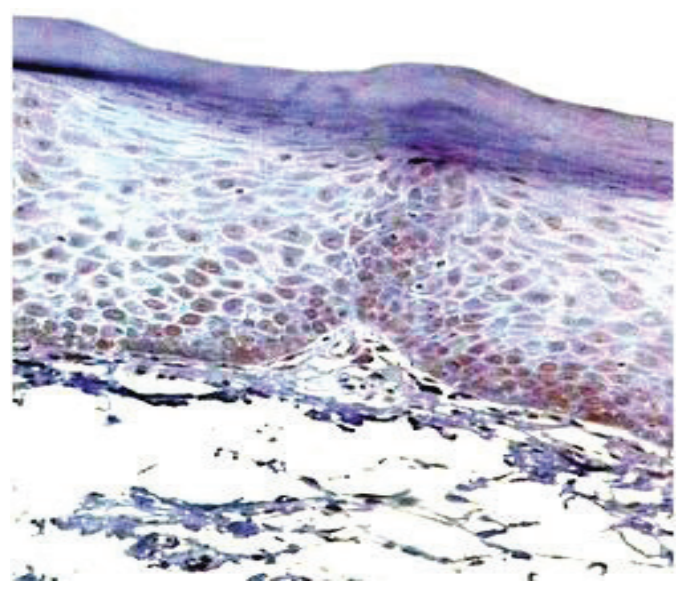

Fonte: Autoria própria 


\section{RESULTADOS}

\section{Teste com azul de toluidina}

Não foi observada relação estatisticamente significante entre a coloração do azul de toluidina e o grau de atipia celular (Tabela 1), exceto para a displasia epitelial severa relacionada significativamente à positividade deste exame (Spearman, $\mathrm{p}<0,05)$. Ver Tabela 1.

Tabela 1 - Resultados obtidos com o azul de toluidina com relação à impregnação do corante e atipia celular

\begin{tabular}{|c|c|c|}
\hline CASO & $\begin{array}{l}\text { RESULTADOS } \\
\text { AZUL TOLUIDINA }\end{array}$ & BIÓPSIA \\
\hline 01 & Heterogênea & $01 \mathrm{~B}(0)$ \\
\hline 02 & Heterogênea & O2B $(0)$ \\
\hline 03 & Heterogênea & 03B (1) \\
\hline 04 & Negativo & 04 \\
\hline 05 & Positivo & 05 \\
\hline 06 & Negativo & 06 \\
\hline 07 & Positivo & 07 \\
\hline 08 & Heterogênea & $08 \mathrm{~B}(0)$ \\
\hline 09 & Heterogênea & O9B (1) \\
\hline 10 & Positivo & 10 \\
\hline 11 & Heterogênea & $11 \mathrm{~B}(0)$ \\
\hline 12 & Heterogênea & $12 B(0)$ \\
\hline
\end{tabular}

Fonte: Dados desta pesquisa.

\section{Análise histopatológica}

Gradação histológica foi estabelecida de acordo com os critérios definidos por Bànócz e Csiba ${ }^{23}$ para displasias epiteliais. Não foi observada relação estatisticamente significante entre a positividade clínica do azul de toluidina e a graduação histológica das displasias. Ver Figura 4.

Figura 4 - Distribuição entre áreas biopsiadas coradas e não coradas pelo azul de toluidina e o diagnóstico histopatológico.

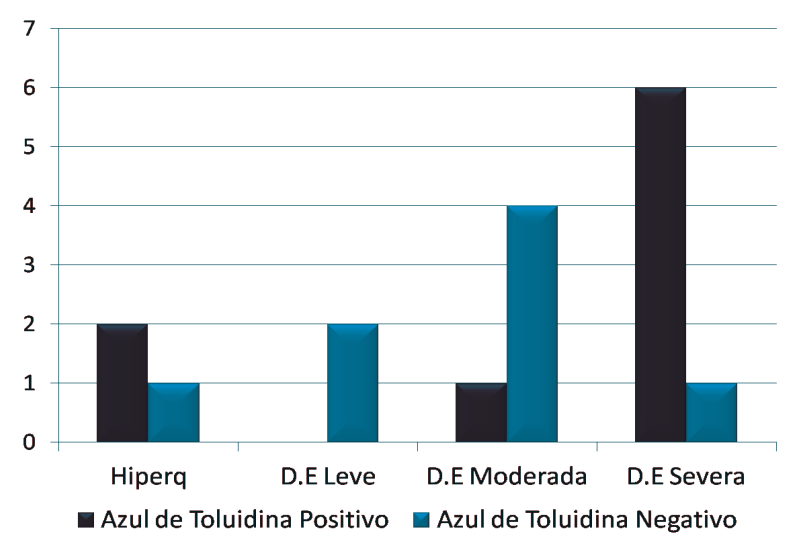

Fonte: Dados desta pesquisa.

\section{Marcação imuno-histoquímica}

Não foi observada relação entre a marcação clínica do azul de toluidina, o grau de displasia da lesão e a imunoexpressão da Ciclina D1 em leucoplasias da mucosa bucal. Ver Tabela 2.

Tabela 2 - Relação entre a marcação do AT, o grau de displasia da lesão e a imunoexpressão da Ciclina D1

\begin{tabular}{l|l|}
$\begin{array}{l}\text { Contagem de } 1000 \text { Células } \\
\text { Casos Ciclina D1(+) }\end{array}$ \\
\hline $01 \mathrm{~A}$ & $6,0 \%$ \\
$01 \mathrm{~B}$ & $12,3 \%$ \\
$02 \mathrm{~A}$ & $13,3 \%$ \\
02B & - \\
$03 \mathrm{~A}$ & $2,9 \%$ \\
$03 \mathrm{~B}$ & $2,3 \%$ \\
\hline 04 & - \\
\hline 05 & $40,2 \%$ \\
\hline 06 & $6,0 \%$ \\
\hline 07 & $0,6 \%$ \\
\hline $08 \mathrm{~A}$ & $0,0 \%$ \\
\hline $08 \mathrm{~B}$ & $5,2 \%$ \\
\hline 10 & $17,5 \%$ \\
\hline $11 \mathrm{~A}$ & $2,7 \%$ \\
\hline $11 \mathrm{~B}$ & $4,5 \%$ \\
\hline $12 \mathrm{~A}$ & $5,2 \%$ \\
\hline $12 \mathrm{~B}$ & $14,3 \%$ \\
\hline
\end{tabular}

Fonte: Dados desta pesquisa

\section{DISCUSSÃO}

A leucoplasia oral (LO) é uma condição comum na mucosa bucal, com transformação maligna que varia de $3 \%$ a $17 \%{ }^{24}$. Para Van der Waal ${ }^{25}$, não existem estudos clínico-patológicos confiáveis ou fatores de previsão moleculares de transformação maligna. Entretanto, essa análise somente pode ser finalizada após a remoção cirúrgica das LO, através de biópsia incisional ou excisional. Daí acreditarmos que essa conduta terapêutica seria a mais apropriada para os pacientes com lesões leucoplásicas da cavidade bucal. Após a análise histopatológica dessas lesões, podem ser traçados esquemas de acompanhamento clínico adequados à necessidade individual dos pacientes, ou até mesmo podem ser planejadas novas intervenções cirúrgicas, quando, por exemplo, biópsias incisionais de lesões extensas revelarem a presença de $D E$, indicando um potencial biológico mais agressivo.

Em relação ao comportamento biológico das LO, alguns autores afirmam que o risco de malignização dessas lesões teria relação com o sítio bucal em que elas se apresentam e com hábitos nocivos à mucosa como o uso de tabaco e (ou) álcool. Segundo dados epidemiológicos, a prevalência geral de leucoplasia varia de 0,6\% a 4,6\% e é mais comum em homens de idade média e avançada ${ }^{21}$. O câncer irá se desenvolver a partir de LO em 1a 20\% dos 
casos. Os principais ativadores da cancerização são fatores exógenos, como tabagismo, álcool, vírus do papiloma humano ou hábitos mastigatórios ${ }^{26}$. De acordo com estudos clínicos, o local mais comum de transformação maligna de leucoplasia é o assoalho da cavidade oral ${ }^{27}$.

Neste estudo, não foi observada relação entre a coloração do azul de toluidina e o grau de atipia celular, exceto para a DE severa. Tendo em vista que a técnica do azul de toluidina é sensível em diagnosticar LO de graus severos de DE. Assim como não foi observada relação entre a marcação clínica do AT, o grau de displasia da lesão e a imunoexpressão da Ciclina D1 em leucoplasias da mucosa bucal. Foram diagnosticados sete casos de displasia severa, tendo o azul de toluidina marcação positiva em 06 deles, o que aponta para uma maior sensibilidade do AT para o diagnóstico da displasia severa com uma sensibilidade de $85,7 \%$. Em $100 \%$ dos casos em que foram realizadas biópsias em dois sítios da mesma lesão, o corante confirmou sua qualidade em marcar áreas de maior atipia celular da lesão. Esse dado reforça o uso do AT como uma ferramenta clínica para auxiliar o profissional na seleção do sítio de biópsias de lesões leucoplásicas extensas. Talvez, com uma amostra maior, pudéssemos observar resultados mais elucidativos em relação à sensibilidade e à especificidade do teste pelo azul de toluidina.

Corroborando nosso resultado, o estudo de Chaudhry et al. ${ }^{28}$ mostra que $75 \%$ das lesões positivas para AT foram leucoplasia salpicada, sendo a DE encontrada em $91,6 \%$ dessa amostra. Além disso, a retenção do azul de toluidina foi observada principalmente nas áreas com leucoplasia ${ }^{28-31}$. Rodrigues et al. ${ }^{32}$ acreditam que, em termos evolutivos, a DE representaria um quadro intermediário entre a hiperceratose e o carcinoma in situ, ou carcinoma invasivo, fortalecendo a opinião quanto à necessidade da biópsia e da análise histopatológica, mesmo em lesões brancas em que seja possível o estabelecimento de um fator causal.

Entretanto podem ocorrer falsos negativos ou positivos. Eles podem estar associados à retenção mecânica do corante e não à sua impregnação. Há alguns anos, já havia sido relatado ${ }^{33-35}$ que o corante pode ser retido mecanicamente em regiões como dorso da língua, papilas filiformes, abertura de ductos das glândulas salivares menores do palato e em lesões com irregularidades e fissuras na superfície.

O estudo de Chaudhry et al. ${ }^{28}$ mostrou que, de 68 lesões negativas, $38(55,9 \%)$ foram diagnosticadas como displásicas, resultando em um alto número de falsos negativos, o que revela um contraste com o resultado de Epstein et al. ${ }^{34}$, em que falsos negativos foram $0 \%$. O grau de displasia nos falsos negativos foi de grau leve, em $92 \%$ das lesões. O mecanismo de ação tem sido controvérso. Embora o azul de toluidina tenha afinidade com os ácidos nucléicos, o arranjo aleatório das células tumorais, devido à perda de coesão, também facilita a penetração e a retenção do corante nos espaços intercelulares. ${ }^{2} \mathrm{Em}$ contrapartida, na leucoplasia homogênea, uma espessa camada de queratina acaba impedindo a penetração do corante, resultando em um teste falso negativo. Esse resultado também pode ser devido ao fato de a camada superficial da queratina conter núcleo picnótico ou ser anuclear. A maioria dos trabalhos relatados na literatura considera os resultados da coloração com o azul de toluidina satisfatórios.

A ciclina D1 é expressa em células epiteliais na transição G1-S do ciclo celular ${ }^{36}$. Imuno-histoquimicamente, a expressão da ciclina D1 está localizada na camada parabasal semelhante à $p 63^{37}$. Em certos tipos de células, a ciclina D1 induz a apoptose ${ }^{38}$. 0 aumento da expressão dessa ciclina é sinal de transformação maligna iminente em lesões pré-blastomatosas do trato respiratório superior ${ }^{17}$.

Em contrapartida, em nosso estudo, não foi observada relação entre a marcação clínica do AT e a imunoexpressão da ciclina D1 em leucoplasias da mucosa bucal, o que está de acordo com os resultados encontrados por Shintani et al. ${ }^{39}$ e Ramakrishna et al ${ }^{40}$, nos quais não houve aumento na ciclina D1 com os graus de displasia. Os autores desse último estudo ${ }^{40}$ concluiram que o indíce de ciclina D1 foi maior nos casos de DE, em comparação ao epitélio normal, mas não houve correlação significativa da ciclina D1 com o grau de displasia. Entretanto Kovesi e Szende ${ }^{41}$ observaram aumento da ciclina D1 paralelamente à gravidade da leucoplasia, apontando a possibilidade de que a demonstração imuno-histoquímica desses produtos gênicos possa ser uma ferramenta útil para um prognóstico mais preciso da leucoplasia oral. A transformação maligna da leucoplasia ocorre nos casos em que a displasia parece histológica, lembrando que os carcinomas intraepiteliais ou invasivos desenvolvem-se em $5 \%$ das displasias leves, mas em $43 \%$ das displasias graves ${ }^{7,9,42,43}$. Sendo assim, a expressão da ciclina D1, aqui, pode ser um evento precoce na conversão da lesão não displásica em uma lesão displásica e pode servir como biomarcador da carcinogênese oral. O reconhecimento de eventos que contribuem para a transformação maligna e seu significado prognóstico é de extrema importância para o desenvolvimento de estratégias terapêuticas e preventivas para o câncer bucal.

\section{CONCLUSÃO}

A análise dos resultados do presente trabalho nos permite afirmar:

1. A técnica do azul de toluidina é sensível em diagnosticar leucoplasias que apresentem graus severos de displasia epitelial.

2. Oitenta e dois por cento das lesões estudadas apresentaram displasia epitelial em graus variados, confirmando a necessidade de se realizar o diagnóstico histopatológico das leucoplasias da mucosa bucal e do posterior acompanhamento clínico dos pacientes.

3. Não foi observada relação estatisticamente sig- 
nificante entre a positividade clínica do azul de toluidina e a graduação histológica das displasias. Porém, em $100 \%$ dos casos em que foram realizadas biópsias em dois sítios da mesma lesão, o corante confirmou a sua qualidade em marcar áreas de maior atipia celular.

4. Não foi observada relação entre a marcação clínica do azul de toluidina, o grau de displasia da lesão e a imunoexpressão da Ciclina D1 em leucoplasias da mucosa bucal.

\section{REFERÊNCIAS}

5. INSTITUTO NACIONAL DE CÂNCER (INCA/MS). Estimativa da incidência e mortalidade por câncer no Brasil. Disponível em: <http:// www.inca.gov.br>. Acesso em: 17 ago. 2018

6. REIBEL, J. Prognosis of oral premalignant lesions: significance of clinical histopathological and molecular biological characteristics. Crit. rev. oral biol. med., Boca Raton, v. 14, p. 47-62, 2013.

7. HO, M.W. et al. The clinical determinants of malignant transformation in oral epithelial dysplasia. Oral oncol., Oxford, v. 48, p. 969-976, 2012.

8. SARODE, S.C.; SARODE, G.S.; TUPKARI, J.V. Oral potentially malignant disorders: A proposal for terminology and definition with review of literature. J. oral maxillofac. pathol., Chennai, v. 18, n.4, p. 77-80, 2014.

9. EL-NAGGAR, A.K. et al. WHO classification of head and neck tumours. 4th ed. France: International Agency for Research on Cancer (IARC), 2017.

10. JIN, L. J. et al. Global burden of oral diseases: emerging concepts, management and interplay with systemic health. Oral dis., Houndmills, v. 22, n.7, p. 609-619, 2016.

11. LIU, W. et al. Oral cancer development in patients with leukoplakia--clinicopathological factors affecting outcome. PLos ONE, San Francisco, 2012.

12. DANTAS, T. S. et al. Influence of educational level, stage, and histological type on survival of oral cancer in a Brazilian population: a retrospective study of 10 years observation. Medicine, Baltimore, 2016.

13. WARNAKULASURIYA, S. et al. Oral epithelial dysplasia classification systems: predictive value, utility, weaknesses, and scope for improvement. J. oral pathol. med., Copenhagen, v. 37, n.3, p. 127-133, 2008.

14. ANGADI, V.C.; ANGADI, P.V. GLUT-1 immunoexpression in oral epithelial dysplasia, oral squamous cell carcinoma, and verrucous carcinoma. J. oral sci., Tokyo, v. 57, p. 115-122, 2015.

15. SCULLY, C.; FIELD, J.K.; TANZAWA H. Genetic aberrations in oral or head and neck squamous cell carcinoma 2: chromosomal aberrations. Oral oncol., Oxford, v. 36, n.4, p. 311-327, 2000.

16. TODD, R. et al. Cell cycle dysregulation in oral cancer. Crit. rev. oral biol. med., Boca Raton, v. 13, p. 51-61, 2002.

17. HAN, E.K. et al. Roles of cyclin D1 and related genes in growth inhibition, senescence and apoptosis. Apoptosis, London, v. 4, n.3, p. 213-219, 1999.

18. WON, K. A. et al. Growth-regulated expression of D-type cyclin genes in human diploid fibroblasts. Proc. Natl. Acad. Sci. U. S. A., Washington, v. 89, n.201, p. 9910-9914, 1992.

19. FRACCHIOLLA, N. S. et al. Molecular and immunohistochemical analysis of the bcl-1/cyclin D1 gene in laryngeal squamous cell carci- nomas: correlation of protein expression with lymph node metastases and advanced clinical stage. Cancer, [S.I], v. 79, n.6, p. 1114-1121, 1997.

20. KOVESI, G. SZENDE, B. Changes in apoptotic and mitotic index, p53 and Ki67 expression in various types of oral leukoplakia.Oncology, [S.I], v. 65, n. 4, p. 331-336, 2003.

21. TASHIRO, E. et al. Overexpression of cyclin D1 contributes to malignancy by upregulation of fibroblast growth fator receptor via pRB/E2F pathway. Cancer res,, Baltimore, v. 63, p. 424-431, 2003.

22. DIEHL, J. A. et al. Hsc-70 regulates accumulation of cyclin D1 and cyclin D1 dependent protein kinase. Mol. cell biol., New York, v. 23, p. 1764-1774, 2003.

23. кҮОМОтО, R. et al. Cyclin D1 gene amplification is a more potent prognostic factor than its protein over-expression in human head and neck squamous cell carcinomas. Int. j. cancer, New York, v. 74, n.6, p. 576-581, 1997.

24. ONOFRE, M. A.; SPOSTO, M.R.; NAVARRO, C.M. Reliability of toluidine blue application in the detection of oral epithelial dysplasia and in situ and invasive squamous cell carcinomas. Oral surg. oral med. oral pathol. oral radiol. endod., St. Louis, v. 91, p. 535-540, 2001.

25. HADZIC, S. et al. Importance of early detection of potentially malignant lesions in the prevention of oral cancer. Mater. sociomed., Saravejo, v. 29, n. 2, p. 129-133, 2017.

26. NIEBEL, H. H., CHOMET, B. In vivo staining test for delineation of oral intraepithelial neoplastic change: preliminary report. J. am. dent. assoc., Chicago, v. 68, p. 801-806, 1964.

27. BÁNÓCZY, J. ; CSIBA, A. Occurence of epithelial dysplasia in oral leukoplakia. Oral surg. oral med. oral pathol., St. Louis, v. 42, n. 6, p. 766-774, 1976.

28. NAPIER, S. S.; SPEIGHT, P. M. Natural history of potentially malignant oral lesions and conditions: an overview of the literature. J. oral pathol. med., Copenhagen, v. 37, n. 1, p. 1-10, 2008.

29. VAND DER WAAL, I. Oral potentially malignant disorders: is malignant transformation predictable and preventable? Med. oral patol. oral cir. bucal, Valencia, v. 19, n. 4, p. 386-390, 2014.

30. SHIU, M. N. et al. Risk factors for leucoplacia and malignant transformation to oral carcinoma: a leukoplakia cohort in Taiwan. Br. j. cancer, London, v. 82, n. 11, p. $1871-1874,2009$.

31. KILT, T. J. et al. Genetic abnormalities in oral leukoplakia and oral cancer progression. Asian pac. j. cancer prev., Bangkok, v. 17, n. 6, p. 3001-3006, 2016.

32. CHAUDHRY, A. et al. Comparison of chemiluminescence and toluidine blue in the diagnosis of dysplasia in leukoplakia: a cross-sectional study. J. Invest. Clin. Dent., Australia, v. 7, n.2, p. 132-140, 2016.

33. RAM, S.; SIAR, C. H. Chemiluminescence as a diagnostic aid in the detection of oral cancer and potentially malignant epithelial lesions. Int. j. oral maxillofac. surg, Copenhagen, v. 34, n.5, p. 521-527, 2005.

34. RAJMOHAN, M. et al. Assessment of oral mucosa in normal, precancer and cancer using chemiluminescent illumination, toluidine blue supravital staining and oral exfoliative cytology. J. oral maxillofac. pathol., India, v. 16, p. 325-329, 2012.

35. SHARMA, N.; MUBEEN. Non-invasive diagnostic tools in early detection of oral epithelial dysplasia. J. Clin. Exp. Dent., Spain, v. 3, p. 184-188, 2011.

36. RODRIGUES, T. L. C. et al. Leucoplasias bucais: relação clínico-histopatológica. Pesqui. Odontol.. bras., São Paulo, v. 14, n. 4, p. 357-361, 2000. 
37. SILVERMAN, S. J., MIGLIORATI, C., BARBOSA, J. Toluidine blue staining in the detection of oral precancerous and malignant lesions. Oral surg. oral med. oral pathol., St. Louis, v. 4, p. 379-382, 1984.

38. EPSTEIN, J. B., ZHANG, L., ROSIN, M. Advances in the diagnosis of oral premalignant and malignant lesions. J. can. dent. assoc, Ottawa, $v$. 68, n. 10, p. 617-621, 2002.

39. CHACRA, J. J.; LEHN, C. N.; CAMPI, J. P. B. et al. Detecção precoce do câncer de cavidade oral pela coloração do azul de toluidina. Acta oncol. bras., São Paulo, v.14, n. 1, p. 31-34, 1994.

40. BRATKOWA, J. et al. Pattern of D type cyclin expression and G1 regulation in human head and neck cancer. Cancer res., Baltimore, v. 55, p. 949-956, 1995.

41. LIU, S.C.; KLEIN-SZANTO, A. J. P. Markers of proliferation in normal and leukoplakic oral epithelia. Oral oncol., Oxford, v. 36, n.2, p. 145151, 2000.

42. KATELNIKOV, V. M. et al. Cyclin D1 expression in squamous cell car- cinomas of head and neck and in oral mucosa in relation to proliferation and apoptosis. Clin. cancer res., Philadelphia, v. 3, p. 95-101, 1997.

43. SHINTANI, S. et al. Expression of cell cycle control proteins in normal epithelium, premalignant and malignant lesions of oral cavity. Oral oncol., Oxford, v. 38, p. 235-243, 2002.

44. RAMAKRISHNA, A. et al. Cyclin D1 an early biomarker in oral carcinogenesis. J. Oral Maxillofac. Pathol., India, v.17, n. 3, p. 351-357, 2013.

45. KOVESI, G.; SZENDE, B. Prognostic value of cyclin D1, p27, and p63 in oral leukoplakia. J. oral pathol. med., Copenhagen, v. 35, n.5, p. 274-277, 2006.

46. BUKHARD, A. Premaligne vera nderungen der mundschleimhaut. Pathologe, Berlin, v. 6, p. 126-132, 1985.

47. KRAMER, I. R. et al. Definition of leukoplakia and related lesions: an aid to studies on oral precancer. Oral surg. oral med. oral pathol., St. Louis, v. 46, n. 4, p. 518-539, 1978.

Submetido em:19/11/2018

Aceito em: 29/11/2018 